\title{
The Nature of Information Security of Living and Non-Living Objects
}

\author{
Sergii Lysenko
}

\begin{abstract}
The author sees synergetics as a very interesting scientific approach to cognition. It seems to be particularly effective in combining the theories of legal and natural sciences, for the simultaneous study of the laws of society and the universe. For the purpose of his study of the possibilities of this theory, the author will use synergetics in defining information processes, and especially in the field of information security. Therefore, considering the conceptual foundations of synergetics, the emphasis will be shifted not so much to the study of the mechanisms of self-organization of the information society as to the exploration of its management capabilities. This is especially important in the context of the coexistence of organizational and self-organizing components, the reduction of the role of anthropogenic factor, the ability to exist in full entropy and to predict bifurcation periods.

In this article, the author will try to investigate the natural genesis of information accumulation, natural ways of storing information and known storage devices. However, by comparing the natural and the artificial, ways of transmitting and stealing information from natural and technical storage devices will be considered. An analogy will be made between psychological intervention in the human mind (hypnosis, magic) to obtain information from the brain or subconscious mind and modern hacking attacks for the same purposes.
\end{abstract}

Keywords: synergetics, information processes, anthropogenic factor, ways of transmitting, subconscious mind.

\section{INTRODUCTION}

There is a lot of scientific debate surrounding information law, and especially information security. It is attractive to think that humanity is closely linked, and even completely dependent on the availability and circulation of the total amount of information, becomes more meaningful. The current era was called informational. But this does not mean that the interests and activities of the Earth's population will be narrowly targeted and will be to create, maintain and maintain information processes. On the contrary, most scientific trends will integrate and transmit their theories to each other, creating new, more grounded knowledge.

The narrow disciplinary approach to understanding the concepts of information, its circulation, preservation and information security is not relevant at present. Ukrainian scientist V. Lipkan argues for the need for a synergistic approach to learning about these phenomena. In this regard, I would like to recall his statements about the early emergence and development of synergy of knowledge, especially legal ones. He pointed out that during the formation of the information society, synergetics, and especially synergetic semiotics, gained more weight. He defined the latter as a

Revised Manuscript Received on November 15, 2019

* Correspondence Author

Sergii Lysenko, Dr. Law, Professor, Severodonetsk Institute of "Interregional Academy of Personnel Management" synergetic of information processes defined in the relevant rules of law. Self-organization remains a form of formation, existence and development of humanity, and information becomes its content. Scientists sometimes criticize synergetics in that it does not have its own subject and method, but is a collection of methods and knowledge that has been borrowed from various scientific disciplines [3].

\section{RESULTS AND DISCUSSIONS}

According to Yu.A. Danilov, modern synergetics has become a recognized interdisciplinary field of research, which deals with the study of complex systems, which, in turn, consist of many elements, parts, components that interact in a complex way [4].

In the context of this theory, Belyakov K.'s view is useful, and he noted that general laws of being, which are considered by philosophy and mathematics, are manifested in human life. Therefore, issues related to the person, the perception of the world around him, is just such a complex of issues, which requires a special methodology, capable of revealing these connections and interactions that have started to develop today. The scientist calls her the theory of interdisciplinary research [5].

At the same time, according to Kagan MS, the first task of scientific and philosophical thought is in the deep development of the methodology of interdisciplinary studies of man, together with an adequate system of combining the structure of the world, which will open to science new paths unknown to all its past history [6]. An interdisciplinary approach makes it necessary to combine, on the one hand, philosophical, psychological, pedagogical, ethical, aesthetic, cultural, legal, and, on the other, physical, mathematical, cybernetic and other aspects of its analysis. Hence the need to solve the most difficult task - to develop a methodology for combining the humanities as human sciences, not only with social sciences and cultural studies, but also with the natural sciences [5].

Continuing the opinions of the respected scientists, the author proposes to consider the necessity and essence of existence of all living, in terms of the available motive and purpose. As is known from the qualification of any event or inaction, it is characterized by a certain composition, which includes the object, subject, objective and subjective parties. With the first two components, everything is clear - the participants of the event and what the event is aimed at. The third component reflects the algorithm of the event and its course. But, the fourth component, for this study, is a matter for separate study. The last component should reflect the motive and purpose of any action.

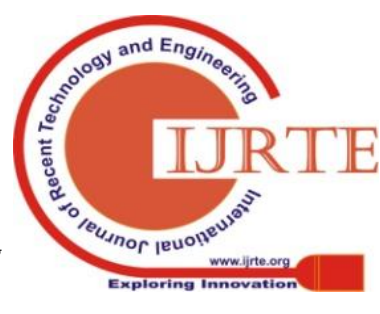


Lowering the theological tenets, it is difficult to imagine that plants, animals, and eventually humans, would appear without a specific purpose and purpose. The skeptical view inherent in the currents of scientific realism does not allow one to leave such a global event for the sake of a case related to a major explosion or natural cataclysm, such as warming, the occurrence of land, accidental bonding of DNA chains and so on.

The meaning of consideration of this question arises only after applying a special analysis of everything existing on earth in terms of the creation, exchange, storage and accumulation of information. Regardless of the source, we wonder about the need for the emergence of all life on Earth and the need for evolution in exactly the form that we have now.

The genesis of civilization was accompanied by tremendous progress in human knowledge in many fields. Ancient scientists have collected a lot of information about wildlife. One of the greatest sages of the ancient world, Aristotle, in his vast "History of Animals" and other treatises, not only collected, but also systematized this information. He has many outstanding discoveries, each of which, even after two thousand years, would have honored the most brilliant scientist, but his knowledge is considered negligible if one considers the entire amount of information available in the world [1].

It is clear that scientists, referring to the observations of the outside world, initially interpreted their own and others' observations, accumulating knowledge and information, naively and unconsciously. The Buffon familiar to us argued that food stocks created by bees and ants should not be considered a manifestation of "reasonableness" and "foresight" - at least because the volume of these stocks clearly exceeds the needs of the bee or ant family. Buffon generally called for the exclusion from the description of animal behavior such concepts as "reason", "understanding", "love", "hatred", "shame" and the like manifestations of anthropomorphism [10]. And why not imagine that each of the living creatures, unknowingly stores in itself certain information, and having reached a sufficient level of development, implements its own, previously laid, information program.

However, the great renegade of Descartes made an attempt to consistently reject anthropomorphism a hundred years before Buffon. He argued that animals have no psyche at all, they are automatic machines, all actions of which are caused by their device, as the movement of the clock and the battle of the clock - the design of the clock mechanism [1]. That is, again we are talking about the realization of the accumulated information for a specific purpose and purpose. But this naturally came to the conclusion: the ultimate goal will become clear to us when we properly study the device and functioning of the bodies of all living things. And Descartes did not forget to draw that conclusion.

A few words must be said to avoid misunderstanding. The idea of developing the human mind from the mind of ancestral animals really logically derives from Darwin's evolutionary theory. It is completely consistent with everything we know about human and animal behavior. That is not only the facts that were known a century and a half ago, but also all those that were established later. This idea has become an axiom in scientific synergy. Today, apparently, there will be no scientist dealing with this topic, which would deny the natural origin of the human mind.

If we acknowledge that a certain being is evolutionarily derived from another, that does not mean that the second has nothing that would not be in the first. The wing of the bird comes from the anterior extremity of the reptile, and ultimately from the fin of the Cypriot fish. However, this does not mean that there is no difference between them, or that this difference is reduced to purely quantitative differences. Flowering plants come from green algae, but it is unlikely that anyone in the mind will hope to pick apples and nuts or at least make firewood from pond wool. Among other things, to consider the assertion that the second comes from the first is tantamount to the assertion that the second is in fact the same as the first means, in fact, to deny evolution, which, following this logic, can create nothing fundamentally new!

It becomes apparent that throughout evolution, information has not only been transmitted from one creature to another by reproduction, but has also been accumulated over the lifespan of a particular species of evolution chain. And after accumulation, too, it was transmitted already in a systematic form to posterity. And what is so unclear about this? After all, if the higher animals are descended from the lower animals, we can assume that the characteristic luggage of information is only a modifying complication of the previous information of the simpler beings.

Developing this thought, you can explain the presence of certain behavior from the beginning. Ameb, jellyfish and echinoderms are strongly denied by the author in any sense, and for the first two he hesitates to even try to add them to creations with instinct. Most of all, they are a set of purely reflex actions, depending on the information received and accumulated in advance, and the program. Descriptions of the existence of these creatures form a picture of the continuous progressive accumulation of information abilities of animals - from the lower to the higher.

The following question can be considered as an example. And can not other than the proposed way to explain the behavior of simple animals? Here, for example, it is known that some small freshwater crustaceans, such as some daphnies, are kept mostly in the less lighted bottom layers of water during the day. Of course, it is impossible to explain this preference by analogy with man. Moreover, every single Daphnia does not choose where to go. Most likely, daylight directed at it excites chemical processes in its nervous system, and it forces the muscles to swing and paddle harder and more often. Daphnia moves erratically, but in the light of this movement increases, and in the shadows - weakens. As a result, with a uniform distribution of Daphnia across the whole area, the rate from light to shadow will move more crustaceans than from shadow to light - as long as the difference in concentration of Daphnia in the light and in the shadow does not balance the difference in their activity. This example clearly resembles the operation of a small computer program, with simple conditions for the implementation of a separate amount of information. In general, there is no psychology, a minimum of physiological assumptions, basically - pure physics of molecular-statistical models of Maxwell and Boltzman! Compared to this simple and clear scheme, even the concept of reflex, which implies a strict correspondence between external influence and response,

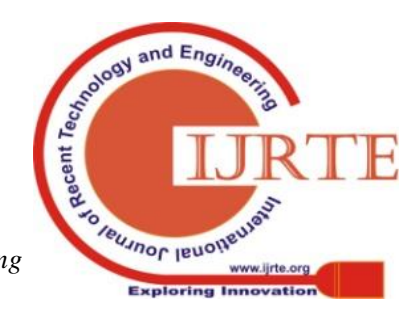


seems unnecessary complication or a special case. In addition, the presence of a reflex requires at least some nervous system, and mechanisms of the type described above may exist even in unicellular ones. It is unclear, however, why the same Daphnia still remains in the water column, rather than stuffing themselves under rocks and snags, where the illumination is even lower. But, probably, there, near the bottom, also includes any tropism, information program, by analogy with the reactions of plants.

Representing all evolution as a process of accumulation, systematization, transmission and storage of important information, the similarity of the process with Occam's razor strikes - one of the most well-known and universal rules of scientific methodology: when the facts allow for several possible explanations, the simplest and most necessary choice the least hypothetical assumptions [1]. We can say that we are seeing a separate case of Occam's razor, focused on the fulfillment of information security tasks in a planetary sense.

Thus, it can be argued with great certainty that an individual cell, an animal's brain and a person's brain are information stores. The simpler organisms are, such as, basic flash drives or hard drives. Animals and humans resemble complex computer systems with power or life systems, memory blocks for systematization and accumulation of information. They even have the function of removing negative or unnecessary information.

If you take a purely elementary approach, then a single-celled organism is almost no different from a flash drive. The first and the second are made of atoms and molecules. What is something like inanimate objects is due to chemical and electro-magnetic reactions. In the end, the former and the latter serve, as we have almost proved, for the purpose of accumulating and transmitting information, the former through the DNA genome, the latter through file data.

American biologist and psychophysiologist Cleve Baxter has proven his theory and ability to perceive information and distinguish it into positive and harmful plants. In his book Biocommunication with Plants ... he described how he connected the sensors of electro-dermal activity of human skin, commonly used in polygraphs, to the leaves of plants. Along with the plant, it emitted different sounds and transmitted information, then observed the change in the electrical conductivity of the leaf surface of the plants. He noted that a soulless creature, a common plant, changed the electrical conductivity of the surface of its leaves, depending on the influence of information [9]. How can this be explained more easily, except the approach suggested by the author, is unknown!

Therefore, having considered the above arguments, it can be stated that all nature and living creatures have been reproduced, developed and existed for the sole purpose and purpose of creating, accumulating, transmitting and retaining useful information for them. Although, to whom this information may be useful, it is necessary to study further. Recalling the legal structure of the event, the author wants to suggest this subjective side, as a simple explanation of the existence of the living. The only thing that is not quite clear to us yet, what is it for? Next, the author will try to develop this opinion and analyze the evolution of information security in terms of the proposed synergy, interdisciplinary approach.

By translating it into more accessible language, the author assumes that there is objectively a force, field, interaction, radiation, or macro-quantum phenomena in the universe that can interact with both living and non-living matter and which has a number of unusual properties. These include range, pronounced information properties, the possibility of information impact on matter, the transfer of the properties of some materials on the environment, and more. Both devices and humans can generate and perceive this power through the impact of information.

In the classical paradigm, it is believed that social evolution occurs solely through the development of tools. The history of the development of Western civilization is the history of the development of tools and technologies. Not the traditional paradigm gives an alternative understanding of social evolution - it is the development of the abilities of living beings. Man has become the defining element and is the focus of all processes. Therefore, threats to information security in the form of psychological influences such as magic, hypnosis and others have been targeted at the person as the most powerful medium of information.

The author hopes that he has quite clearly stated his point of view as from the beginning of the onset of life on earth, everything was aimed at the accumulation, reproduction, transmission and storage of information about himself and the world around him. From the beginning of the emergence of chains of proteins that were composed of DNA, it is clear that they are nothing but a collection of certain information about what creation from this DNA will evolve. Recent studies, in general, have shown that information in DNA strands is encrypted using a binary code, such as computer databases. The subsequent evolution of organisms, from unicellular to plants and animals, occurred on the principle of complication, depending on the need to preserve more complex and meaningful information. That is, everything went from simple to complex, as in our time computer, cybernetic technology is developing. To us, it is easier to understand, because the whole evolution of modern cybernetics has passed into modern humanity before our eyes, in some sixty years.In the living world, everything went according to the same plan, only slightly slower, it took 100 or 200 billion years.

In arguing this point, it should be noted that along with the evolution of nature, let's call it information, evolved and threats to this information security. Together with threats, information security measures were in place.

Since, in ancient times, man was the main carrier of information, so threats to information security were directed at him. Given the fact that the human brain is responsible for obtaining, analyzing and storing information, then the brain was targeted by the aggressors. This refers to the use of magic, hypnosis and other techniques to influence the human brain. If you think about it, they were always used solely for this purpose, as the author stated above. Moreover, they resemble the techniques used to use modern virus programs and hacking techniques.

The magic of religions, mainly European, has in recent times been given a specific development, a certain coexistence with church dogma and numerous persecutions, which have played the role of measures to fight for information security. This struggle took many forms: the persecution of heresies, the suppression of existing beliefs and cults, the Crusades and the Inquisition. 
And this applies not only to Christianity, but also to Islam.

The most reasonable thought belongs to Sergiy Kernbach, from the Swiss University, who at the exoteric level of religion struggled with each other and monotheism gradually superseded polytheism, then at the esoteric level the various spheres of magic successfully coexisted and complemented each other. During this period, the emergence of important magical theories and systems. First, it's alchemy. Although alchemy is attributed to a long history, its roots are in the period of early monotheism. Second, Christian dogma created the image of the devil and associated evil with him. This was followed by an explanation of a magical act with a higher essence as a contract with the devil and the emergence of black magic. Third, folk magic that has never disappeared has been transformed into a phenomenon of arrogance. This happened again not without the influence of the church and its Inquisition. Fourth, the Jewish system, which was practically forgotten, suddenly received a new impetus [7].

Agree that everything described is very similar to our time, the emergence of viruses and hacking programs aimed at stealing or corrupting information in artificial computers created by man.

Moreover, along with threats, information security tools have been developed. There was a division into black and white magic, the introduction of all that philosophical context and white by information security experts. Simply, all the attackers were called evil, from which black magic should draw its power. It is opposed to the good that embodies security.

Good and evil, in this regard, are two sides of the same coin, as there are no interests without threats to those interests, and they cannot exist without each other. That is, if there is no interest, there will be no threat to it. Similarly, with one god being better, the other becoming worse - the concept of evil as the fundamental idea of black magic emerged from this context. There would be no intruders, no need to create information security for living things. As we can see, in ancient times, as in the past, certain specialists, not related to a wide circle, priests, magicians and others, were engaged in information security.

At the end of XX - beginning of XXI century there was a new technological revolution, aimed at increasing the possibilities for processing and transfer of information, scientists say that the information society has emerged. Many contemporary works from different fields of knowledge reflect a new understanding of the world, thus replacing the non-traditional sciences in this world. These works must first be attributed to quantum physics [11]. Biological and biophysical studies should also be mentioned. The work of philosophers of the XIX and XX centuries, such as Vernadsky and Sheldrake, made a great contribution in their attempt to rethink the universe [12]. All disciplines that have become unconventional, including magic, parapsychology, and psychotronics, have responded to this new trend.

The basic provisions of the modern information system resemble, in general terms, von Neumann's computational model. Energy is similar to information and by itself does not take any action. There is management information that is similar to a computer program. It is she who determines what action and what object to take. Only in the presence of a certain information program can energy do any work. The information itself is massless and perhaps spreads faster than that we mean by black magic. Black was used by malefactors

light. Any object, including a living organism, can act as a control information carrier. This fairly common concept for the world of computers has several far-reaching consequences. First, a computing architecture is required to run the information program. There have been many works comparing the Universe to a super-large quantum computer [13] or treating the Universe as a hologram. Quite aptly described such a picture of Isaac Asimov in his work "The Last Question". It was about a distant future, dominated by a supercomputer that existed beyond matter and space, he knew all the questions and ruled all his life. Then life disappeared, the universe disappeared in our understanding. The computer became lonely. Further it is better to quote.

"All other questions have long been resolved, but until the answer to this last question is received, the computer could not, had no right to breathe easily and go into oblivion. All the necessary data has already been collected. There was nothing else to collect anymore. But this collected information still had to be sorted, analyzed and brought into the system.

It took some premature time.

Finally, the Computer learned how to reverse the direction of the entropy boom. But there was no one left to whom the Computer could give the answer. However, it doesn't matter. The answer was so comprehensive that during its demonstration, this difficult situation would also be allowed.

During another premature interval, Computer was thinking about how best to organize the case. Then he carefully composed the program. The consciousness of the Computer captured everything that had once been the universe, and focused on what was now chaos. Step by step everything will be done.

\section{And the Computer said: - LET IT BE LIGHT!}

And it was light ...

And on the seventh day he rested ..." [16].

Interestingly, magic can also be interpreted in this terminology. Secondly, the information program can be transmitted from anywhere to any place. Getting into an energy-rich environment, this program gets started. Some of the psychotronic and information-magic techniques are built on this principle. Moreover, remote transmission of information can occur instantaneously, in accordance with the principle of quantum entanglement in macroscopic systems. Phantoms, also known as inanimate entities, are considered within this concept to be small standalone applications, similar to modern smartphones. They can be created, programmed and used as assistants. Third, an information program transmitted by a biological organism affects that organism. Changing this program can affect the body itself.

The field of application of this principle is quite wide, moreover, phenomena such as "bad eye", "damage" and the like, are getting a new interpretation in the form of "pathological" or "negative" programs. There is also a new interpretation of the effect of the experimenter, who consciously or unconsciously transfers his emotional or behavioral "programs" into the experimental situation.

Since information is closely related to entropy, within the framework of information theory, a very popular trend has emerged, related to changing entropy properties of systems.

Published By: 
Modern works investigate the relationship between the physicochemical properties of objects and the effects on their entropic characteristics.

In Western parapsychology, a popular information model has remained the postulate of morphogenetic fields [14], which should be a major factor in the transmission of information. The most commonly used is the notion of information matrix, which is an analog of the Computer-Universe. And lately there has been an interesting tendency for a more tolerant coexistence of magic and parapsychology, for example, the study of magical techniques through instrumental methods is more frequent. The magic itself in this concept of the information model is called cybermagic or energy information magic.

Quite interesting, in the context of this theory, is the effect of the transfer of information influence. It is caused by the phenomenon when two objects are under the influence of high-transmitting radiation, with one object acquiring some properties of another object without coming into direct physical contact with it. Here are some examples to understand what this is all about. Using manganese, nickel and niobium as the first object when using this effect in metallurgy, molten steel has alloying properties, although there is no physical contact with alloying substances [15]. When used as the first object of vaccines for influenza and hepatitis A and B, after 36 hours in the blood of another detected antibodies of these vaccines. However, the vaccine was not physically administered to patients and the like.

It has already been proven that high-transmittance radiation is a prerequisite for the effect of information transfer. Experiments have shown that it can be of both natural and artificial origin. The author is not yet aware of experiments where this condition was not fulfilled. Often, as the first, used water, for example, for watering plants or feeding animals. Such activation of water is effective only in the scheme of local influences.

\section{CONCLUSIONS}

The preliminary analysis shows that during the evolution of all living things, depending on the need to reproduce and transmit information, the moment came when living USB drives and computers (single-celled and multicellular organisms) ceased to cope with the tasks. Information reached such sizes when it became necessary to analyze it so quickly that the most perfect natural medium of information a person with a built-in computer in the form of a brain, did not meet the goal. That's when, according to the author, using the accumulated information, people, while executing a perfect information program, invented an artificial way to accumulate, transmit and store additional information to their brain. It is understood that modern flash drives, computers, the Internet and databases were invented.

The information evolution of nature has already gone the separate way, not giving artificial devices the emotions and instincts that used to serve them for their own and information security. Natural carriers of information began to improve with the help of the aforementioned inanimate means, people began to improve themselves or cyber-organization began. Although, recently, all the prerequisites for the creation and emergence of artificial intelligence, which is called artificial, taking into account the topic of the article, appeared only conditional. Perhaps over a period of time, he will dominate the Earth and create a new intelligence that will be artificial for him too. And so on, catching up with the need to handle more and more information.

Thus, studying the nature of the very matter of information, its formation, circulation and security, it will become quite simple to build a legal framework for information law, as well as to develop an effective information security strategy of the modern world. Administrative and legal mechanisms of information security will be able to be based on the principles of reasonableness for simplicity, in accordance with the revealed rules of the synergistic approach. And the adoption of new regulations will be able to resist the laws of order and harmony inherent in the universe, serving, first and foremost, members of this world, not a small bunch of beneficiaries.

\section{REFERENCES}

1. B. Zhukov, Introduction to Behavior. M. - AST Publishing House, 2017. 400s.

2. Lipkan VA, Maksimenko Yu. E., Zhelikhovsky VM Information Security of Ukraine in the Conditions of European Integration: Textbook. - K .: CST, 2006. - 280 p.

3. Lipkan VA, Fundamentals of Terrology, K. FOP Lipkan - 2006. 70p.

4. Danilov Yu.A., German Haken on synergetics // Synergetic paradigm. Nonlinear thinking in science and art. - M .: Progress-Tradition, 2002. - p. 22.

5. KI Belyakov, Security Knowledge: Problems of Definition and Methodology, K. - 2007. UDC 343.3 (447).

6. Kagan MS Prospects for the development of the humanities in the $21 \mathrm{st}$ century. <http://anthropology.ru/en/texts/kagan/symp12_01.html>.

7. Kernbach S., Supernatural, scientifically proven facts. - 2010.

8. S.A.Migunov, E.P.Sidorov, A.V.Trogorov. Reflexogenic mechanism of action of spectral irradiator SPECTO-P on immobilized enzyme systems. Reflexology, 1 (1): 14-17, 2006.

9. Cleve Bacster, "Primary Perception. Biocommunication with Plants, Living Foods, and Human Cells," White Rose Millennium Press, 2003, 168 pages, www.primaryperception.com

10. Georges Louis Leclerc de Buffon, The Universal and Private Natural History, - Librock URSS, 2012, - 384s.

11. Freetief Capra. Tao of Physics. ORIS, SHE-PRINT, 1994.

12. AV Savelyev, The newest paradigm of computer magic. In Sat. works IV International.

13. Seth Lloyd. Programming the Universe. Alpina Non-Fiction, 2013.

14. A.G.Gurwitsch. Uber den Begriffdes embryonalen Feldes. Roux Arch. Ent. Org. 51: pp.383-415, 1922.

15. AV Klyuev, SA Kurapov, VF Panov, and VV Strelkov. Structure and mechanical properties of metal after melt treatment in a non-stationary electromagnetic field of a wave emitter. Metal Science, Heat Treatment of Metals, (7 (649)): 3-9, 2009.

16. Asimov Isaac, The Last Problem. - 1956.

17. Tkach, B. P., \& Urmancheva, L. B. (2009). Numerical-analytic method for finding solutions of systems with distributed parameters and integral condition. Nonlinear Oscillations, 12(1), 113-122. doi:10.1007/s11072-009-0064-6

18. Chornei, R., Hans Daduna, V. M., \& Knopov, P. (2005). Controlled markov fields with finite state space on graphs. Stochastic Models, 21(4), 847-874. doi:10.1080/15326340500294520

19. Chalyy, K.A., Bulavin, L.A., Chekhun, V.F., (...), Tsekhmister, Ya.V., Chernenko, L.M. (2009). Fundamentals and medical applications of neutron and light spectroscopy of confined liquids. IFMBE Proceedings. https://link.springer.com/chapter/10.1007/978-3-642-03895-2_57

20. Chalyy, K. A.; Bulavin, L. A.; Chekhun, V. F. (2009). Fundamentals and Medical Applications of Neutron and Light Spectroscopy of Confined Liquids. 11th International Congress of the IUPESM/World Congress on Medical Physics and Biomedical Engineering: Munich, GERMANY публ.: SEP 07-12, 2009 IUPESM; Int Org Med Phys (IOMP). WORLD CONGRESS ON MEDICAL PHYSICS AND BIOMEDICAL ENGINEERING, VOL 25, PT 13 : IFMBE Proceedings. 
The Nature of Information Security of Living and Non-Living Objects

21. Lacan, Jacques. L'Homme aux Loups. Séminaire 1951-1952. / Lacan J. Écrits techniques. — Paris: A.L.I., 1999. — P. 481 496.

22. Lacan, Jacques. Problèmes cruciaux pour la psychanalyse. Séminaire 1964-1965. — Paris: A.L.I.

\section{AUTHORS PROFILE}

Sergii Lysenko, Dr. Law, Professor, Severodonetsk Institute of "Interregional Academy of Personnel Management" 